Article

\title{
A Snapshot of European Children's Eating Habits: Results from the Fourth Round of the WHO European Childhood Obesity Surveillance Initiative (COSI)
}

\author{
Julianne Williams ${ }^{1, *}$, Marta Buoncristiano ${ }^{1}$, Paola Nardone ${ }^{2}{ }^{-}$, Ana Isabel Rito ${ }^{3} \mathbb{C}$, \\ Angela Spinelli ${ }^{2}$, Tatjana Hejgaard ${ }^{4}$, Lene Kierkegaard ${ }^{5}$, Eha Nurk ${ }^{6}$, Marie Kunešová ${ }^{7}$, \\ Sanja Musić Milanović ${ }^{8}$, Marta García-Solano ${ }^{9}$, Enrique Gutiérrez-González ${ }^{9}$, \\ Lacramioara Aurelia Brinduse ${ }^{10}{ }^{\circledR}$, Alexandra Cucu ${ }^{10}$, Anna Fijałkowska ${ }^{11}$, \\ Victoria Farrugia Sant'Angelo ${ }^{12}$, Shynar Abdrakhmanova ${ }^{13}$ (i), Iveta Pudule ${ }^{14}$, \\ Vesselka Duleva ${ }^{15}$, Nazan Yardim ${ }^{16}$, Andrea Gualtieri ${ }^{17}$, Mirjam Heinen ${ }^{18}$, \\ Silvia Bel-Serrat $\left.{ }^{18}{ }^{(}\right)$, Zhamyla Usupova ${ }^{19}$, Valentina Peterkova ${ }^{20}$, Lela Shengelia ${ }^{21}$,
} Jolanda Hyska ${ }^{22}$, Maya Tanrygulyyeva ${ }^{23}$, Ausra Petrauskiene ${ }^{24}{ }^{(\mathbb{D}}$, Sanavbar Rakhmatullaeva ${ }^{25}$, Enisa Kujundzic ${ }^{26}$, Sergej M. Ostojic ${ }^{27}{ }^{(\mathbb{D}}$, Daniel Weghuber ${ }^{28}{ }^{(\mathbb{C}}$, Marina Melkumova ${ }^{29}$, Igor Spiroski ${ }^{30}$, Gregor Starc ${ }^{31}$, Harry Rutter ${ }^{32}{ }^{-}$, Giulia Rathmes ${ }^{1}$, Anne Charlotte Bunge ${ }^{1}$, Ivo Rakovac ${ }^{1}{ }^{1}$, Khadichamo Boymatova ${ }^{33}$, Martin Weber ${ }^{34}$ and João Breda ${ }^{1}{ }^{\mathbb{D}}$

1 WHO European Office for the Prevention and Control of Noncommunicable Diseases, 125009 Moscow, Russian Federation; buoncristianom@who.int (M.B.); giuliarathmes@icloud.com (G.R.); anne-charlotte.bunge@charite.de (A.C.B.); rakovaci@who.int (I.R.); rodriguesdasilvabred@who.int (J.B.) Italian National Institute of Health (Istituto Superiore Di Sanità), 00161 Rome, Italy; paola.nardone@iss.it (P.N.); angela.spinelli@iss.it (A.S.)

3 National Institute of Health Dr. Ricardo Jorge, 1600560 Lisbon, Portugal; ana.rito@insa.min-saude.pt

4 Danish Health Authority, 2300 Copenhagen S, Denmark; thv@sst.dk

5 National Institute of Public Health, University of Southern Denmark, 1455 Copenhagen K, Denmark; leki@sdu.dk

6 Department of Nutrition Research, National Institute for Health Development, 11619 Tallinn, Estonia; eha.nurk@tai.ee

7 Institute of Endocrinology, Obesity Unit, 11694 Prague, Czechia; mkunesova@endo.cz

8 Croatian Institute of Public Health, University of Zagreb, School of Medicine, 10000 Zagreb, Croatia; sanja.music@hzjz.hr

9 Spanish Agency for Food Safety and Nutrition, 28014 Madrid, Spain; mgarcias@mscbs.es (M.G.-S.); egutierrez@mscbs.es (E.G.-G.)

10 Department of Public Health and Management, University of Medicine and Pharmacy Carol Davila, 030167 Bucharest, Romania; lbrinduse@gmail.com (L.A.B.); alexandra.cucu@insp.gov.ro (A.C.)

11 Department of Cardiology, Institute of Mother and Child, 01-211 Warsaw, Poland; anna.fijalkowska@imid.med.pl

12 Primary Health Care, Ministry for Health, 1940 Floriana, Malta; victoria.farrugia-santangelo@gov.mt

13 National Center of Public health, Ministry of Health of the Republic of Kazakhstan, 010000 Nur-Sultan City, Kazakhstan; shynar_a@mail.ru

14 Centre for Disease Prevention and Control, LV-1005 Latvia, Riga; iveta.pudule@spkc.gov.lv

15 National Center of Public Health and Analyses, 1431 Sofia, Bulgaria; v.duleva@ncpha.government.bg

16 Turkish Ministry of Health, Public Health General Directorate, 34400 Istanbul, Turkey; nazan.yardim@saglik.gov.tr

17 Health Authority, Department of Health and Social Security, 47893 San Marino, San Marino; andrea.gualtieri.authority@pa.sm

18 National Nutrition Surveillance Centre, University College Dublin, Dublin, Ireland; mirjam.heinen@ucd.ie (M.H.); silvia.belserrat@ucd.ie (S.B.-S.)

19 Republican Center for Health Promotion and Mass Communication, 720040 Bishkek, Kyrgyzstan; jama.usupova@mail.ru

20 Institute of Paediatric Endocrinology, National Medical Research Centre for Endocrinology of the Ministry of Health of the Russian Federation, 117036 Moscow, Russian Federation; peterkovava@hotmail.com 
21 National Center for Disease Control and Public Health of Georgia, 0198 Tbilisi, Georgia; 1.shengelia@ncdc.ge

22 Institute of Public Health, 1007 Tirana, Albania; lhyska2002@yahoo.it

23 Internal Diseases Department of the Scientific Clinical Centre of Mother and Child Health, 744036 Ashgabat, Turkmenistan; ovezmyradovag@who.int

24 Department of Preventive Medicine, Lithuanian University of Health Sciences, 44307 Kaunas, Lithuania; ausra.petrauskiene@lsmuni.lt

25 Department for Organization of Health Services to Children, Mothers, Adolescents and Family Planning, Ministry of Health and Social Protection of Population, 734025 Dushanbe, Tajikistan; sanavbar2010@list.ru

26

30 Institute of Public Health, Faculty of Medicine, Ss. Cyril and Methodius University, 1000 Skopje, North Macedonia; i.spiroski@iph.mk

31 Faculty of Sport, University of Ljubljana, 1000 Ljubljana, Slovenia; gregor.starc@fsp.uni-lj.si

32 Department of Social and Policy Sciences, University of Bath, Bath BA2 7AY, UK; hr526@bath.ac.uk

33 WHO Country Office for Tajikistan, 734019 Dushanbe, Tajikistan; boymatovak@who.int

34 WHO Child and Adolescent Health and Development, WHO Regional Office for Europe, 2100 Copenhagen, Denmark; weberm@who.int

* Correspondence: williamsj@who.int

Received: 3 July 2020; Accepted: 4 August 2020; Published: 17 August 2020

\begin{abstract}
Consuming a healthy diet in childhood helps to protect against malnutrition and noncommunicable diseases (NCDs). This cross-sectional study described the diets of 132,489 children aged six to nine years from 23 countries participating in round four (2015-2017) of the WHO European Childhood Obesity Surveillance Initiative (COSI). Children's parents or caregivers were asked to complete a questionnaire that contained indicators of energy-balance-related behaviors (including diet). For each country, we calculated the percentage of children who consumed breakfast, fruit, vegetables, sweet snacks or soft drinks "every day", "most days (four to six days per week)", "some days (one to three days per week)", or "never or less than once a week". We reported these results stratified by country, sex, and region. On a daily basis, most children (78.5\%) consumed breakfast, fewer than half $(42.5 \%)$ consumed fruit, fewer than a quarter $(22.6 \%)$ consumed fresh vegetables, and around one in ten consumed sweet snacks or soft drinks ( $10.3 \%$ and $9.4 \%$, respectively); however, there were large between-country differences. This paper highlights an urgent need to create healthier food and drink environments, reinforce health systems to promote healthy diets, and continue to support child nutrition and obesity surveillance.
\end{abstract}

Keywords: nutrition; child; obesity; surveillance; health; noncommunicable diseases; children; fruit; vegetables; soft drinks

\title{
1. Introduction
}

It is important for a child to eat a healthy diet in order to prevent malnutrition (stunting, wasting, micronutrient deficiencies, obesity) and noncommunicable diseases (NCDs) [1,2]. Low-quality diets are now believed to be the single biggest risk factor for the global burden of disease [3]. In recent decades, changes in dietary patterns and physical activity behaviors have been identified as likely contributors to a rise in childhood obesity [4,5]. Research from the latest round of the WHO European Childhood Obesity Surveillance Initiative (COSI) carried out in 2015-2017 indicates that 29\% of boys and 27\% of girls aged seven to nine years had overweight and there was a prevalence of obesity of $12 \%$ in boys and $9 \%$ in girls [6]. At the same time, in certain parts of the WHO European Region, there is a double 
burden of malnutrition, characterized by the coexistence of undernutrition (being underweight for one's age, too short for one's age (stunted), too thin for one's height (wasted), or deficient in vitamins and minerals (micronutrient malnutrition)), along with overweight, obesity, or noncommunicable diseases, within individuals, households, and populations, and across the life course $[7,8]$.

The prevalence of overweight and obesity is increasing worldwide [9]. According to the WHO Global Monitoring Framework for NCDs, which is a set of 25 indicators and 9 voluntary targets are used to track progress toward reaching global targets in 2015-2020, not a single country in the WHO European Region is likely to meet Global Monitoring Target 7, which aims to "halt the rise in diabetes and obesity" [10].

Ensuring that children consume healthy diets is important for achieving the UN Sustainable Development Goals (SDGs) related to no hunger (SDG Goal 2), good health and well-being (SDG Goal 3), quality education (SDG Goal 4), no poverty (SDG Goal 1), economic growth (SDG Goal 8), and more [11,12]. Food preferences and eating habits established in childhood and adolescence tend to be maintained into adulthood [13], making nutrition in childhood an important public health issue.

A healthy diet includes adequate quantities and appropriate proportions of fruit, vegetables, legumes (e.g., lentils and beans), nuts, and whole grains [14], and limits the intake of free sugars [15,16], salt [17], saturated fats, and highly processed foods. A healthy diet eliminates trans fats of all kinds. Consumption of sugar-sweetened beverages should be limited, as it has been associated with increased body weight [18] and dental caries [19].

The WHO European Childhood Obesity Surveillance Initiative provides data on the eating behaviors of children across the WHO European Region. Established in 2007, COSI collects high-quality data on the childhood obesity prevalence and energy-balance-related behaviors [20]. These data enable countries to set national targets, monitor trends over time, make comparisons between countries, and over time, to evaluate the effectiveness of obesity prevention efforts. In addition to collecting high-quality anthropometric measurements from primary-school-aged children, COSI also collects information on children's dietary and physical activity patterns, screen time, sleep, and more.

Given the importance of nutrition in childhood, alongside the rising trend in childhood obesity, this study used the most recent results from the COSI study to describe the eating behaviors of children aged 6-9 years from across the WHO European Region.

\section{Materials and Methods}

Data were collected between 2015 and 2017, as part of COSI round four. Among the thirty-six countries participating in round four, 23 of them collected information on children's dietary behaviors using parental reports on a "family form". These countries were: Albania, Bulgaria, Croatia, Czechia, Denmark, Georgia, Ireland, Italy, Kazakhstan, Kyrgyzstan, Lithuania, Latvia, Malta, Montenegro, Poland, Portugal, Romania, Russian Federation (Moscow only), San Marino, Spain, Tajikistan, Turkey, and Turkmenistan. Children's parents or caregivers were asked to complete a questionnaire that contained indicators of energy-balance-related behaviors (including diet) and family socioeconomic status. Completion of the form was voluntary and participants could opt out or choose not to participate at any time.

The COSI study follows the International Ethical Guidelines for Biomedical Research Involving Human Subjects [21]. Local ethics approval was also granted. Details for this approval are found in Supplementary Box S1. More details on the data collection procedures are provided elsewhere $[20,22,23]$.

Parents were asked: "over a typical or usual week, how often does your child eat or drink the following kinds of foods or beverages"? This was followed by a tick box, where parents answered "never", "less than once a week", "some days (1-3 days)", "most days (4-6 days)", or "every day". Parents were asked to report on a number of food items, shown in Supplementary Figure S1. For this paper, we reported on the consumption of fresh fruits, vegetables (excluding potatoes), savory snacks (e.g., potato crisps, corn chips, popcorn, peanuts), sweet treats (e.g., candy bars or chocolates), and sugar-containing soft drinks. These questions were selected because they provided a summary 
that was related to common sources of nutrients of interest [24]. Countries chose country-specific examples for the food examples for "savory snacks (like potato crisps, corn chips, popcorn, peanuts)", or "sweets (like candy bars or chocolate)". These examples were identified by leading nutrition experts within the country and approved by the government-appointed principal investigator of the study. All questionnaires were translated from English into the local language, and then back-translated into English to check for discrepancies with the original English form.

For each country, we calculated the percentage of children who consumed these foods "every day", "most days (four to six days per week)", "some days (one to three days per week)", or "never or less than once a week". We reported these results stratified by country, sex, and region. Geographic regions were based on the United Nations Standard Geographical regions, which are based on continental regions and are further subdivided into sub-regions and intermediary regions that are drawn to obtain greater homogeneity in the sizes of the population, demographic circumstances, and accuracy of demographic statistics [25]. We did not include sub-regional pooled estimates because these subregions include countries that are not participating in COSI, and therefore a sub-regional estimate would not provide an accurate assessment of the situation in that geographical area.

For each variable, we calculated the frequency of consumption according to country and sex. We tested for differences between sex in the distribution of the responses using the Rao-Scott chi-square test, a design-adjusted version of the Pearson's $\chi^{2}$ test. We applied post-stratification weights to adjust for the sampling design, oversampling, and nonresponse proportions in order to infer results from the sample of the population. These were available and applied for all countries, with the one exception of Lithuania, where an unweighted analysis was carried out. All analyses took account of the complex survey nature of the data (i.e., multiple stages, clustering, and stratification). Pooled estimates were calculated, including only one target age group per country in order to balance the contribution of each country to the pooled estimates and to limit the differences in children's age as much as possible. An adjusting factor was applied to the post-stratification weights to take account of differences in the population sizes of the countries involved. The adjusting factor was based on the number of children belonging to the targeted age group according to Eurostat figures or national official statistics for 2016.

A $p$-value of 0.05 was used to define statistical significance. All statistical analyses were performed in the statistical software package Stata version 15.1 (StataCorp LLC, College Station, TX, USA).

\section{Results}

A total of 132,489 children from 23 countries were included in the analysis. The number of participants per country varied widely, from 306 children in San Marino to 43,696 in Italy (Table 1). Most of the children (75.2\%) were seven years of age and 51.3\% were boys.

The pooled estimates indicated that most children $(78.8 \%)$ consumed breakfast every day, but around 2.3\% consumed breakfast "never or less than once a week" and $8.6 \%$ consumed breakfast only on "some days" (one to three days a week). The pooled estimates indicated that $42.5 \%$ of children consumed fresh fruit "every day" and 7.5\% "never consumed it or consumed it less than once a week". Around a quarter (22.6\%) of all children consumed vegetables "every day", and 14.0\% consumed it "never or less than once a week." The pooled estimates indicated that $5.2 \%$ of children consumed savory snacks "every day", but $57.9 \%$ consumed savory snacks "never or less than once a week". Around one in ten children $(10.3 \%)$ consumed sweets "every day" and a third (32.8\%) consumed sweets "never or less than once a week". Around one in ten (9.4\%) children consumed soft drinks every day. 
Table 1. Number of children invited to participate in COSI/WHO Europe Round 4 (2015-2017), the number of children included in the analysis, and the percentage of children participating by sex, age, and country.

\begin{tabular}{|c|c|c|c|c|c|c|c|c|c|c|}
\hline \multirow[t]{2}{*}{ Country $^{a}$} & \multicolumn{2}{|c|}{ Children Invited to Participate ${ }^{\text {b }}$} & \multicolumn{3}{|c|}{ Children Included in the Analysis ${ }^{c}$} & \multicolumn{5}{|c|}{ Percentage of Children Participating by Sex and Age (\%) ${ }^{\mathrm{d}}$} \\
\hline & Total Number & $\begin{array}{l}\text { Proportion Whose Family } \\
\text { Form Was Filled in (\%) }\end{array}$ & Boys $(n)$ & Girls $(n)$ & Total $(n)$ & Boys (\%) & 6-Year-Olds & 7-Year-Olds & 8-Year-Olds & 9-Year-Olds \\
\hline Albania & 7113 & 36.2 & 1315 & 1212 & 2527 & 52.5 & 0.1 & 24.2 & 52.0 & 23.7 \\
\hline Bulgaria & 4090 & 83.1 & 1702 & 1698 & 3400 & 51.5 & 0 & 100.0 & 0 & 0 \\
\hline Croatia $\mathrm{e}$ & 7220 & 76.0 & 1318 & 1333 & 2651 & 51.1 & 0 & 0 & 100.0 & 0 \\
\hline Czechia & n.a. & n.a. & 670 & 736 & 1406 & 50.7 & 49.5 & 50.5 & 0 & 0 \\
\hline Denmark & 3202 & 29.9 & 511 & 446 & 957 & 52.7 & 27.4 & 70.2 & 2.4 & 0 \\
\hline Georgia & 4143 & 78.4 & 1667 & 1579 & 3246 & 51.2 & 1.6 & 85.1 & 13.0 & 0.3 \\
\hline Ireland & 2704 & 32.4 & 438 & 436 & 874 & 52.6 & 38.2 & 60.2 & 1.6 & 0 \\
\hline Italy & 50,902 & 95.2 & 22,425 & 21,271 & 43,696 & 51.5 & 0 & 0.5 & 66.3 & 33.1 \\
\hline Kazakhstan & 6026 & 82.3 & 2149 & 2162 & 4311 & 50.6 & 0 & 0.4 & 51.0 & 48.6 \\
\hline Kyrgyzstan & 8773 & 86.6 & 3798 & 3769 & 7567 & 50.7 & 10.5 & 43.5 & 39.5 & 6.5 \\
\hline Lithuania & 5527 & 69.8 & 1930 & 1882 & 3812 & 50.6 & 0.4 & 66.4 & 33.0 & 0.2 \\
\hline Latvia & 8143 & 71.5 & 2752 & 2955 & 5707 & 48.2 & 7.9 & 43.8 & 9.1 & 39.3 \\
\hline Malta & 4329 & 73.4 & 1589 & 1590 & 3179 & 50.0 & 0.1 & 69.7 & 30.1 & 0.1 \\
\hline Montenegro & 4094 & 66.8 & 1441 & 1295 & 2736 & 52.8 & 31.2 & 48.4 & 20.1 & 0.2 \\
\hline Poland & 3828 & 76.9 & 1451 & 1494 & 2945 & 50.2 & 0 & 0 & 100.0 & 0 \\
\hline Portugal & 7475 & 85.6 & 3167 & 3224 & 6391 & 50.7 & 25.2 & 49.0 & 24.0 & 1.7 \\
\hline Romania & 9094 & 73.6 & 3312 & 3298 & 6610 & 49.1 & 0.4 & 28.4 & 47.5 & 23.8 \\
\hline Russian Federation & 3900 & 52.6 & 1006 & 1046 & 2052 & 50.2 & 18.8 & 72.8 & 8.3 & 0.1 \\
\hline San Marino & 329 & 93.6 & 138 & 168 & 306 & 45.1 & 0 & 0 & 64.7 & 35.3 \\
\hline Spain & 14,908 & 70.1 & 5290 & 5163 & 10,453 & 50.9 & 25.4 & 25.2 & 24.9 & 24.6 \\
\hline Tajikistan & 3502 & 93.5 & 1623 & 1647 & 3270 & 51.6 & 7.7 & 90.8 & 1.4 & 0.2 \\
\hline Turkmenistan & 4085 & 95.3 & 1944 & 1947 & 3891 & 49.9 & 0 & 79.9 & 20.1 & 0 \\
\hline Turkey & 14,164 & 81.7 & 5335 & 5167 & 10,502 & 50.9 & 11.4 & 82.3 & 6.0 & 0.3 \\
\hline Total & 198,683 & 79.5 & 66,971 & 65,518 & 132,489 & 51.3 & 0 & 75.2 & 18.2 & 6.6 \\
\hline
\end{tabular}

n.a.-not available. ${ }^{a}$ Figures refer to primary school children from Albania (ALB), Bulgaria (BUL), Croatia (CRO), Czechia (CZH), Denmark (DEN), Georgia (GEO), Ireland (IRL), Italy (ITA), Kazakhstan (KAZ), Kyrgyzstan (KGZ), Lithuania (LTU), Latvia (LVA), Malta (MAT), Montenegro (MNE), Poland (POL), Portugal (POR), Romania (ROM), Moscow city (RUS), San Marino (SMR), Spain (SPA), Tajikistan (TJK), Turkmenistan (TKM), and Turkey (TUR). ${ }^{b}$ Total figures were calculated including only countries with available information about the number of children invited to participate in the surveillance. ${ }^{c}$ All children with complete information on sex, whose age was between six and nine years old and with information on eating number of children invited to participate in the surveillance. ${ }^{c}$ All children with complete information on sex, whose age was between six and nine years old and with information on eating
habits from the family form. Latvia, Lithuania, Malta, Montenegro, Portugal, Spain, Tajikistan, Turkey, and Turkmenistan; 8-year-olds from Albania, Croatia, Poland, and Romania; and 9-year-olds from Kazakhstan. The figures were estimated by applying post-stratification weights. ${ }^{\text {e }}$ For Croatia, only data on 8-year-olds were available for comparison at the European level. The proportion of children whose parents or caregivers filled in the family form was calculated in the whole sample (not only for 8-year-olds). 


\subsection{Consumption of Breakfast}

The percentage of children who consumed breakfast every day ranged from $48.9 \%$ in Kazakhstan to $96.4 \%$ in Portugal (Figure 1). Between-country and between-region differences in breakfast consumption were not tested for significance, although there were visible between countries and no clear patterns according to region. There were no significant differences in breakfast consumption between boys and girls (Supplementary Table S1).

\subsection{Consumption of Fresh Fruit}

The frequency of consuming fresh fruit everyday ranged widely between the regions. The consumption of fresh fruit every day was highest in the Southern European countries, with $80.8 \%$ in San Marino, $72.6 \%$ in Italy, and $63.1 \%$ in Portugal (Figure 1, Supplementary Table S2). Meanwhile, the daily fresh fruit consumption was low in the Central Asian countries-Kyrgyzstan $18.1 \%$, Kazakhstan 33.3\%, and Tajikistan 33.5\%-with an exception of Turkmenistan with $70.1 \%$. The same trend was visible for differences in the proportion of children who consumed fresh fruit "never or less than once a week", ranging from 3.0\% in San Marino, 3.3\% in Portugal, and 2.2\% in Montenegro to $21.4 \%$ in Tajikistan and $22.6 \%$ in Kyrgyzstan.

There were significant differences in fresh fruit consumption between sexes, with girls more likely to eat fruit on a daily basis compared to boys (Supplementary Table S2).

\subsection{Consumption of Vegetables}

Daily vegetable consumption ranged from $9.1 \%$ in Spain to $68.1 \%$ in Turkmenistan and $74.3 \%$ in San Marino (Figure 2). The percentage of children who consumed vegetables "never or less than once a week" was higher in Western Asian countries, with $20.4 \%$ in Turkey and $17.1 \%$ in Georgia compared with $1.3 \%$ in Czechia and $1.4 \%$ in Turkmenistan. There were significant between-sex differences, with boys tending to eat vegetables less frequently than girls (Supplementary Table S3).

\subsection{Consumption of Savory Snacks (Like Potato Crisps, Corn Chips, Popcorn, or Peanuts)}

We observed large differences between countries and regions of Europe in the frequency of consuming savory snacks like potato crisps, corn chips, popcorn, or peanuts. Low values for the daily consumption of savory snacks were observed in the Northern European countries, where Denmark reported $0 \%$, Lithuania and Latvia $0.6 \%$, and Ireland 1.5\% (Figure 2). In contrast, in the Southern European and Asian countries, daily consumption of savory snacks was more frequently reported. Albania reported a percentage of $21.5 \%$ of children who consumed savory snacks every day, as well as Tajikistan with $11.3 \%$ and Montenegro and Turkmenistan with $9.0 \%$ (Table S4). In Malta, only $7.7 \%$ of the children never or less than once week, while in the Russian Federation, 90.8\% of children consumed these foods "never or less than once a week". Similar results were seen in Lithuania (83.1\% consumed savory snacks "never or less than once a week") and in Latvia ( $80.2 \%$ never or less than once a week). There were no significant differences in the consumption of savory snacks between boys and girls (Supplementary Table S4).

\subsection{Consumption of Sweets (Like Candy Bars or Chocolate)}

Daily consumption of sweet snacks like candy bars or chocolate ranged from $0.4 \%$ in Denmark to $21.1 \%$ in Turkmenistan and 22.8\% in Bulgaria (Figure 2). The percentage of children who never or less than once a week consumed sweet snacks ranged from 3.9\% in Malta to 56.7\% in Spain and $67.8 \%$ in Portugal. There were no clear regional trends in the distribution of daily sweet snack consumption and there were no significant sex differences (Supplementary Table S5). 


\section{Having breakfast}

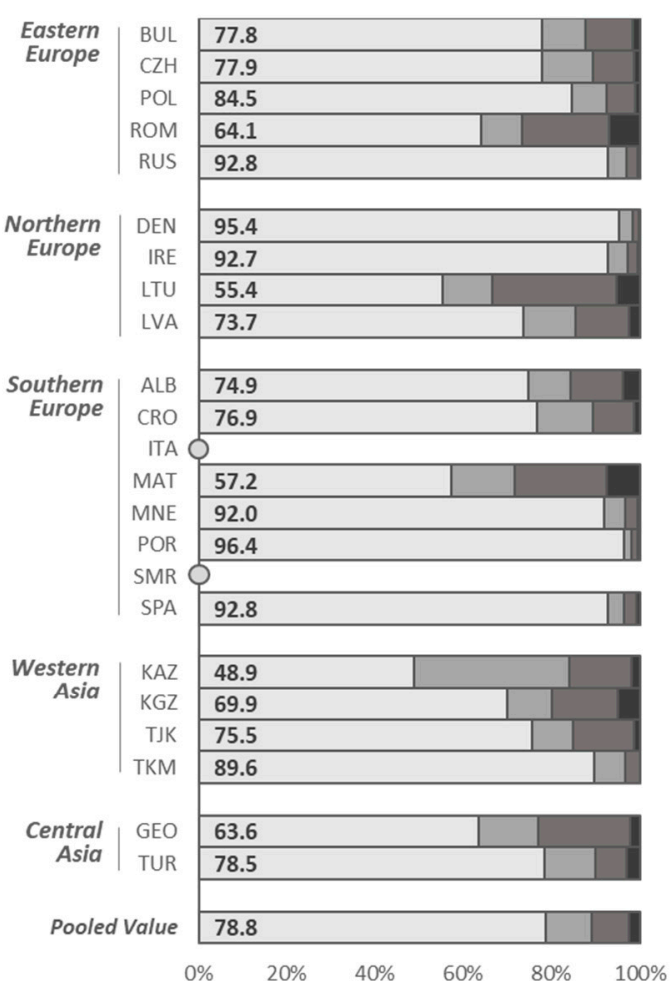

Every day $\square$ Most days (4-6 days)
Consuming fresh fruit
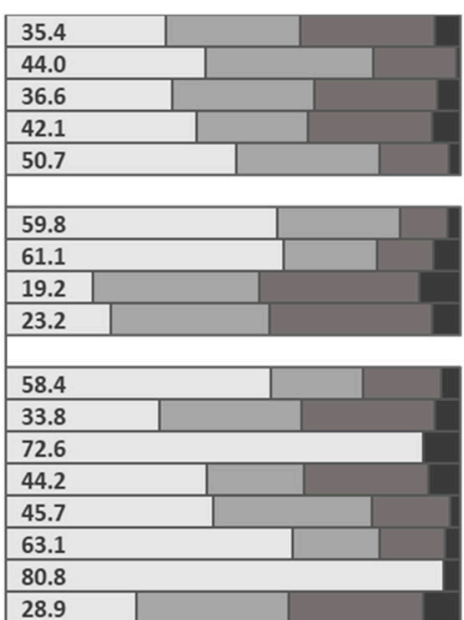

\begin{tabular}{|l|}
\hline 80.8 \\
\hline 28.9 \\
\hline
\end{tabular}
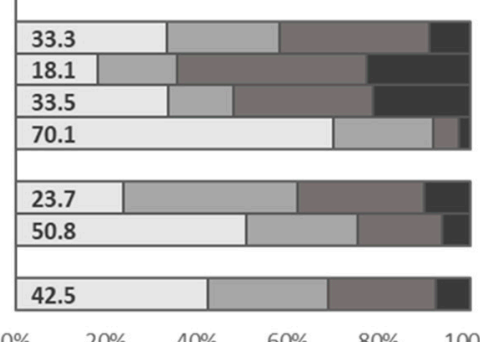

Consuming vegetables

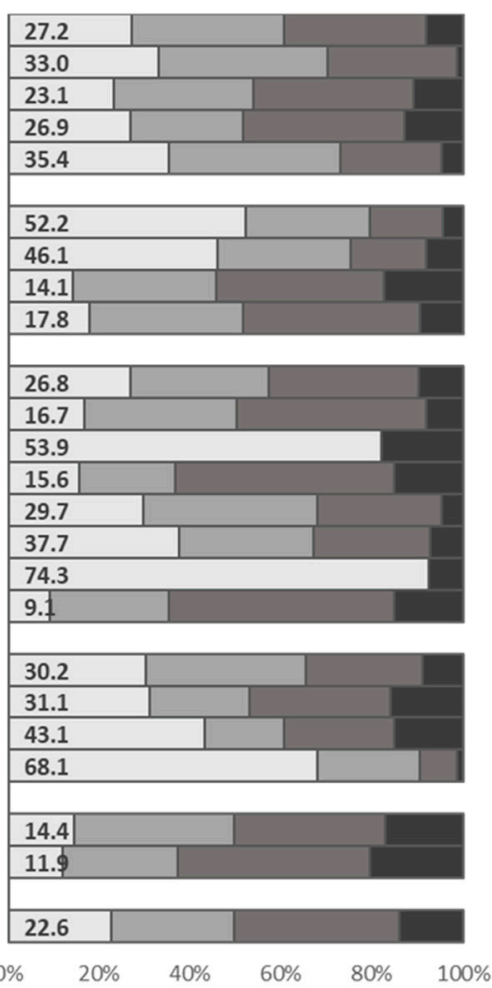

Figure 1. Frequency of consuming breakfast, fresh fruit, and vegetables among boys and girls by country ${ }^{\mathrm{a}}$. COSI/WHO Europe round 4 (2015-2017). ${ }^{\text {a }}$ Pooled values were estimated, including the following age groups/countries: 7-year-olds from Bulgaria, Czechia, Denmark, Kyrgyzstan, Georgia, Ireland, Latvia, Lithuania, Malta, Montenegro, Portugal, Spain, Tajikistan, Turkey, and Turkmenistan; 8-year-olds from Albania, Croatia, Poland, and Romania; and 9-year-olds from Kazakhstan. 
Consuming savory snacks

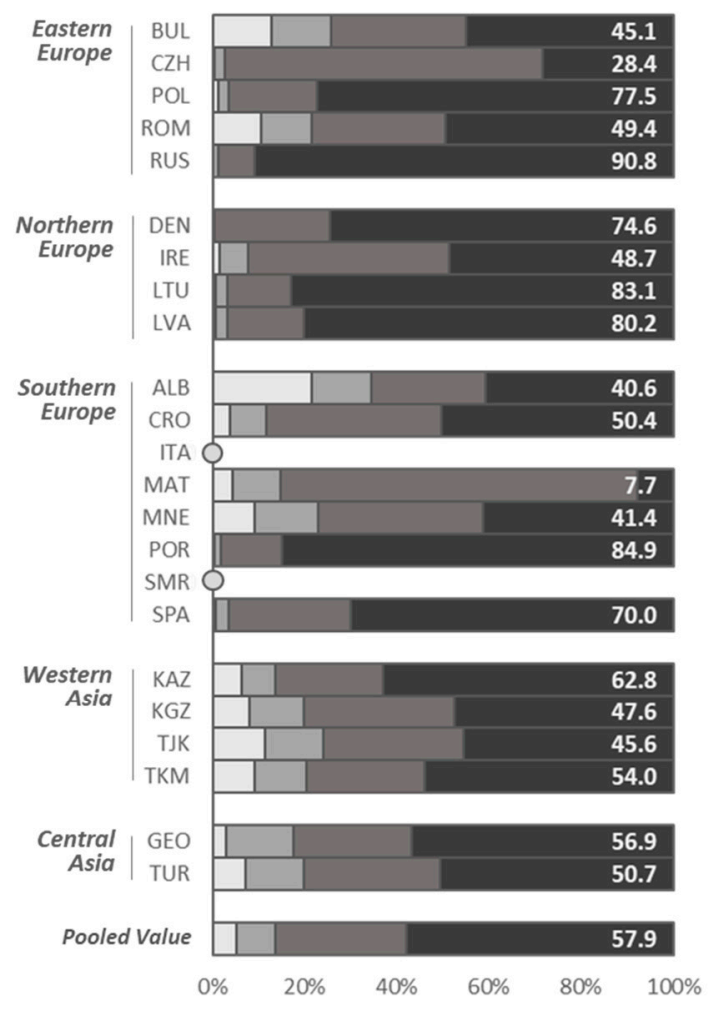

$\square$ Every day $\square$ Most days (4-6 days)
Consuming sweet snacks
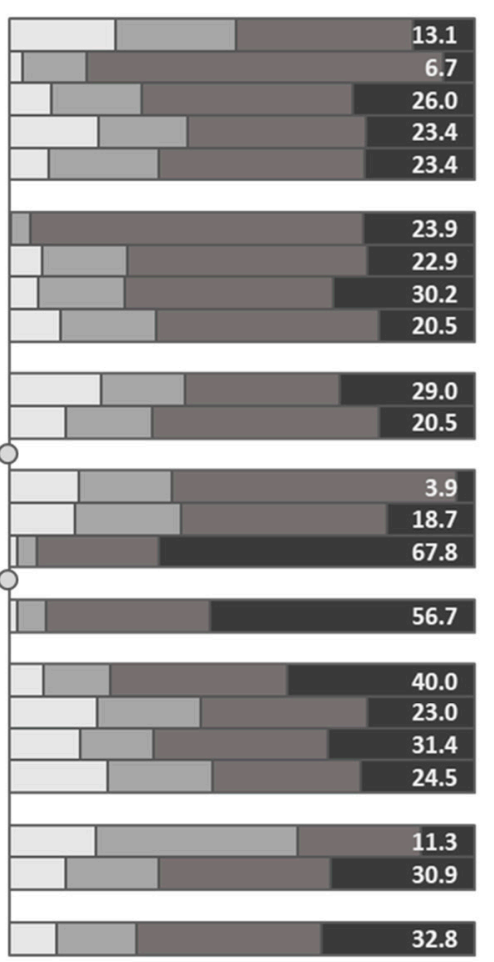

Consuming soft drinks
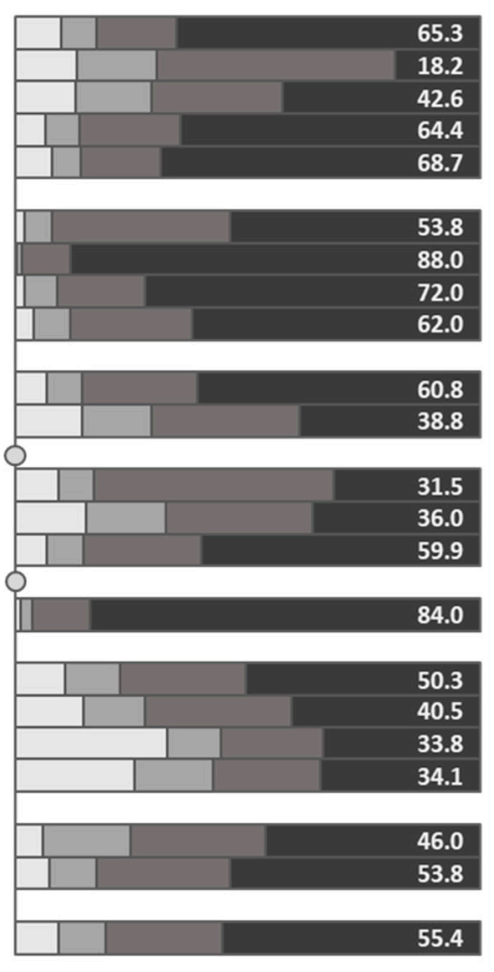

Figure 2. Frequency of consuming savory snacks, sweet snacks, and soft drinks among boys and girls by country a ${ }^{\text {}}$ COSI/WHO Europe round 4 (2015-2017). a Pooled values were estimated, including the following age groups/countries: 7-year-olds from Bulgaria, Czechia, Denmark, Kyrgyzstan, Georgia, Ireland, Latvia, Lithuania, Malta, Montenegro, Portugal, Spain, Tajikistan, Turkey, and Turkmenistan; 8-year-olds from Albania, Croatia, Poland, and Romania; and 9-year-olds from Kazakhstan. 


\subsection{Consumption of Soft Drinks}

The frequency of consuming soft drinks every day was lowest in Northern European countries, with a value of $0.4 \%$ in Ireland, $2.0 \%$ in Lithuania, and $2.1 \%$ in Denmark (Figure 2). In comparison, in the Central Asian countries of Tajikistan (32.8\%) and Turkmenistan (25.8\%), daily soft drink consumption was relatively high among some children. There was a lower percentage of children who never or less than once a week consumed soft drinks in the Central Asian countries (33.8\% in Tajikistan, 34.1\% in Turkmenistan, 40.5\% in Kyrgysztan, 50.3\% in Kazakhstan) compared to the Northern European countries (88.0\% in Ireland, 72.0\% in Lithuania, 62.0\% in Latvia, 53.8\% in Denmark). We observed no significant differences between boys and girls (Supplementary Table S6).

\section{Discussion}

The purpose of this study was to provide a snapshot that updates the general picture of the dietary habits of European children. Our data present a largely confirmatory picture of the current understanding, with some bright spots in terms of dietary habits but also many areas of opportunity.

The bright spots include high levels of breakfast consumption, with around $80 \%$ of children consuming breakfast every day. Daily breakfast consumption was the lowest in Kazakhstan, with fewer than half of the children consuming it every day, whilst almost all the children consumed it every day in Portugal and Denmark. The pooled results align with findings from another systematic review of 286,804 children and adolescents ( 2 to 18 years) living in 33 countries, which found that the prevalence of skipping breakfast ranged from 10-30\%, with an increasing trend in adolescents, especially girls [26]. However, there is also evidence to suggest that breakfast consumption may decrease as children get older. A recent report from the Health Behaviour in School-Aged Children (HBSC) survey of findings from 227,441 young people aged 11, 13, and 15 years living in 45 countries/regions found that more than four out of 10 adolescents do not eat breakfast every school day, and that girls across all ages tend to skip breakfast and eat fewer meals with their family than boys [27].

The areas of opportunity for improving children's diets are related to increasing the consumption of fruits and vegetables. We found that only $42.5 \%$ of children consumed fruit and $22.6 \%$ consumed vegetables on a daily basis, but there were wide between-country differences. Daily fruit consumption ranged from $80.8 \%$ in San Marino to only 18.1\% in Kyrgyzstan and 19.2\% in Lithuania. Three-quarters $(74.3 \%)$ of the children in San Marino consumed fresh vegetables every day compared to $9.1 \%$ of children in Spain, 11.9\% in Turkey, $14.1 \%$ in Lithuania, and 14.4\% in Georgia. Data on fruit and vegetable consumption trends from 33 countries participating in the HBSC surveys from 2002, 2006, and 2010 indicate that many adolescents do not consume fruit and vegetables on a daily basis, but there was an increase in daily fruit and vegetable consumption between 2002 and 2010 in the majority of countries [28]. Even so, findings from the latest HBSC report (2017/2018) found that almost two in three adolescents do not eat enough nutrient-rich foods, such as fruits and vegetables [27]. A recent review on dietary patterns found that among adolescents, the average fruit and vegetable consumption is below recommended levels in almost all populations [29].

This study also highlights the need for continued efforts to discourage the consumption of foods that are high in salt, sugar, and fat, and low in nutritional value. The pooled estimates related to the frequency of consuming savory snacks, sweets, and soft drinks suggest that 5.2\%, 10.3\%, and 9.4\% of children consume these foods daily, respectively, but there was a wide between-country variation. The percentage of children consuming savory snacks every day ranged from $0 \%$ in Denmark and $0.1 \%$ in the Russian Federation to $21.5 \%$ in Albania. Daily consumption of sweet snacks ranged from $0.4 \%$ in Denmark to $21.1 \%$ in Turkmenistan and $22.8 \%$ in Bulgaria. Consumption of daily soft drinks ranged from $0.4 \%$ in Ireland to $32.8 \%$ in Tajikistan. This aligns with similar findings from the latest results from the HBSC, which also indicates that one in four adolescents eat sweets and one in six consume sugary drinks at least once a day [27]. Few available data have been found on savory snack consumption or sodium intake among children, but for the majority of the included populations, levels were far above the recommended five grams per day [29]. 
Based on the data from 23 countries, this study found wide between-country differences in children's healthy and unhealthy eating habits, but few clear patterns according to region. These differences were likely due to a complex range of factors. Eating patterns and food preferences in childhood are shaped by individual, interpersonal, and environmental factors, including a child's family, cultural background, social environment, socioeconomic status, and school environment [30]. Children today are increasingly exposed to environments where energy-dense and nutrient-poor foods are promoted [31] and readily available, which can make eating a healthy diet challenging. Other factors to consider include cultural differences, differences in school food environments, differences in home food environments, differences in family traditions and mealtimes, differences in the level of adherence to national dietary guidelines, price differences (which may affect the affordability and accessibility of healthy or unhealthy foods and differences in the availability of fruit or vegetables), and more.

These data lend further support to existing calls for urgent action to improve child nutrition. Schools may improve nutrition by following quality standards for school meals and providing students with access to healthy foods and beverages (such as fresh fruits, vegetables, and fresh water), and nutrition education [32]. Examples of successful initiatives include the European Union's School Fruit and Vegetable Scheme [33] and the WHO's Nutrition-Friendly Schools Initiative [34].

Another possible action to improve nutrition is through fiscal incentives or subsidies to promote better nutrition, both for encouraging the consumption of healthy foods (such as fruit or vegetables, or discouraging the consumption of unhealthy foods, such as sugary drinks). The United States Department of Agriculture provides reimbursement to states that operate nonprofit breakfast programs in schools [35]. Taxation on sugar-sweetened beverages has been shown to be effective in the reduction of sugar consumption [36,37]. Another potential intervention is the reformulation of processed foods [38], which has shown promise for the reduction of both sugar [39] and salt [40,41].

Current food and beverage marketing practices predominantly promote low-nutrition foods and beverages, and have a direct effect on children's nutrition knowledge, preferences, purchase behavior, consumption patterns, and diet-related health [42]. Governments should restrict the marketing of unhealthy foods to children, particularly in the digital world, where advertising may be especially persuasive [43]. Implementation of the WHO recommendations on the marketing of foods and non-alcoholic beverages to children is one indicator in the Global Monitoring Framework [44].

A comprehensive approach involving action at many levels is required to improve children's diets [45]. In addition to improving food environments (within schools, at home, and in other places where children gather), action is needed to engage parents and other adults who care for children [46]. Parents or caretakers often play a key role in ensuring the availability of nutritious foods, not only at home but also at school (in instances when children bring a packed lunch to school). Parents or caregivers can also help to ensure that children consume appropriate portion sizes, and there may be opportunities for governments to provide better guidance and support for parents and caregivers [47]. Front-of-pack labeling can help provide parents with information to support healthier eating choices and food purchases [48], although a recent Cochrane review suggests that more research may be needed regarding the effects that food labeling may have on consumer choices [49]. Nutritious diets may be more expensive, and this may contribute to socioeconomic disparities in health [50]; therefore, efforts must be made to ensure access to healthy and affordable foods, especially for vulnerable groups. Results from COSI indicate that the prevalence of obesity and severe obesity among children in Europe was common among children whose mothers had a lower level of education [51].

This study had several limitations. First, this study used a dietary questionnaire that has not been validated and which did not collect information on the portion sizes of foods. Future work is needed to validate this questionnaire and identify possible methods of assessing portion sizes of various foods that are consumed per day in order to identify the prevalence of children meeting certain nutrition recommendations (such as consuming five portions of fruits and vegetables per day). Further work is needed to validate questions about "sweets" and "savory snacks" where there may be cultural 
variation in the ways that these categories are understood. Another limitation is that the dietary indicators used in this paper are not comprehensive. For example, we reported here on "sweet treats, such as candy bars or chocolate" but there are other sweet foods, such as "biscuits, cakes, or doughnuts" (Supplementary Figure S1) that were assessed in a separate question but not reported in this paper.

This study was limited by a cross-sectional study design and a reliance on parental reports of children's diet behaviors, which may have limited accuracy [52,53]. Other limitations include possible social desirability bias or non-response bias. We do not know how the responders in this study varied from non-responders, but previous research indicates that healthier individuals with a higher socioeconomic status are more likely to respond to health surveys [54] or dietary surveys [55], and this may result in an overestimation of the prevalence of healthy behaviors. Another limitation is that this study did not account for seasonal differences in the availability of fruit and vegetables; responses to this questionnaire were collected during the autumn, winter, or spring months when fruit and vegetable availability may have been lower than during the summer months, particularly in Central Asia.

One of the main strengths of this study was that it collected data from a large sample of children across a diverse range of countries using nationally-representative sampling methods and following a common protocol.

This project is an ongoing one and will be updated in future years. It is a valuable dataset that represents the collaboration of many committed experts and provides important visibility into the habits of European children. Accurate data on children's weight status, eating habits, and other energy-balance-related behaviors provide a vital underpinning for government actions to implement and evaluate effective and appropriate strategies to combat under-nutrition and obesity. Investment in high-quality surveillance is essential to ensure more children can benefit from good nutrition and improved health during childhood and onward through the life course.

Supplementary Materials: The following are available online at http://www.mdpi.com/2072-6643/12/8/2481/s1, Box S1: Description of national ethics approval for countries featured in this paper who were participating in the WHO European Childhood Obesity Surveillance Initiative (COSI) Round 4 (2015-2017), Table S1: Frequency of breakfast consumption among boys and girls, by country. COSI/WHO Europe Round 4 (2015-17), Table S2: Frequency of fresh fruit consumption among boys and girls, by country. COSI/WHO Europe Round 4 (2015-17), Table S3: Frequency of vegetable consumption among boys and girls, by country. COSI/WHO Europe Round 4 (2015-17), Table S4: Frequency of savory snack consumption among boys and girls, by country. COSI/WHO Europe Round 4 (2015-17), Table S5: Frequency of sweet snacks consumption among boys and girls, by country. COSI/WHO Europe Round 4 (2015-17), Table S6: Frequency of soft drinks consumption among boys and girls, by country. COSI/WHO Europe Round 4 (2015-17), Figure S1: Description of the WHO European Childhood Obesity Surveillance Initiative question related to child dietary habits, COSI Round 4 (2015-17).

Author Contributions: Conceptualization, J.B., M.B., and J.W.; formal analysis: M.B. and J.W.; data curation, M.B. and J.W.; writing—original draft preparation, J.W., G.R., P.N., M.B., and A.C.B.; writing—review and editing, J.W., M.B., P.N., G.R., A.C.B., A.I.R., A.S., T.H., L.K., E.N., M.K., S.M.M., M.G.-S., E.G.-G., L.A.B., A.C., S.M.O., D.W., M.M., H.R., G.R., A.C.B., I.R., S.A., M.H., S.B.-S., J.H., S.R., I.S., G.S., K.B., M.W. and J.B.; supervision, J.B., I.R., A.S., T.H., M.K., S.M.M., A.F., V.F.S., I.P., V.D., N.Y., A.G., Z.U., V.P., L.S., Y.H., M.T., A.P., Z.A., and E.K. All authors have read and agreed to the published version of the manuscript.

Funding: These activities were partially funded through a grant from the Russian Government in the context of the WHO European Office for the Prevention and Control of Noncommunicable Diseases. The authors gratefully acknowledge support from the Danish Ministry of Health, the Italian Ministry of Health and Italian National Institute of Health, the National Institute for Health Development in Estonia, the Health Service Executive in the Republic of Ireland, the Ministry of Health in Bulgaria, the Poland National Health Program (grant no. 6/1/3.1.12/NPZ/2016/106/1401, the Czech Republic (grants AZV MZČR 17-31670 A and MZČR—RVO EÚ 00023761), and the Ministry of Health in Latvia. The Spanish study was funded by the Spanish Agency for Food Safety and Nutrition (AESAN). COSI Austria was supported by a grant from the Federal Ministry of Social Affairs, Health, Care and Consumer Protection, Republic of Austria. COSI Turkey gratefully acknowledges the World Bank for the survey credit. COSI Lithuania gratefully acknowledges the WHO representative in Lithuania, Ingrida Zurlyte, for printing the COSI questionnaires. The study in Kazakhstan was funded by the Ministry of Health of the Republic of Kazakhstan within the scientific and technical program.

Acknowledgments: We gratefully acknowledge support from Liza Villas and Gerben Rienk for making the COSI project possible. We also acknowledge the leadership of the principal investigators from Ireland (Cecily Kelleher), Kyrgyzstan (Gulmira Aitmurzaeva), Romania (Constanta Huidimac Petrescu), and Tajikistan (Zulfiya 
Abdurrahmonova). The authors alone are responsible for the views expressed in this article and they do not necessarily represent the views, decisions or policies of the institutions with which they are affiliated.

Conflicts of Interest: The authors declare no conflict of interest.

Disclaimer: The authors alone are responsible for the views expressed in this article and they do not necessarily represent the views, decisions or policies of the institutions with which they are affiliated.

\section{References}

1. Park, M.H.; Falconer, C.; Viner, R.M.; Kinra, S. The impact of childhood obesity on morbidity and mortality in adulthood: A systematic review. Obes. Rev. 2012, 13, 985-1000. [CrossRef] [PubMed]

2. Wijnhoven, T.M.; van Raaij, J.M.; Spinelli, A.; Starc, G.; Hassapidou, M.; Spiroski, I.; Rutter, H.; Martos, E.; Rito, A.I.; Hovengen, R.; et al. WHO European Childhood Obesity Surveillance Initiative: Body mass index and level of overweight among 6-9-year-old children from school year 2007/2008 to school year 2009/2010. BMC Public Health 2014, 14, 806. [CrossRef]

3. Afshin, A.; Sur, P.J.; Fay, K.A.; Cornaby, L.; Ferrara, G.; Salama, J.S.; Mullany, E.C.; Abate, K.H.; Abbafati, C.; Abebe, Z. Health effects of dietary risks in 195 countries, 1990-2017: A systematic analysis for the Global Burden of Disease Study 2017. Lancet 2019, 393, 1958-1972. [CrossRef]

4. Freemark, M. Determinants of Risk for Childhood Obesity. N. Engl. J. Med. 2018, 379, 1371-1372. [CrossRef] [PubMed]

5. Freemark, M. Childhood obesity in the modern age: Global trends, determinants, complications, and costs. In Pediatric Obesity; Springer: Berlin/Heidelberg, Germany, 2018; pp. 3-24.

6. WHO. WHO European Childhood Obesity Surveillance Initiative: Report of the Fourth Round of Data Collection (2015-2017); WHO: Geneva, Switzerland, 2020.

7. WHO. The Double Burden of Malnutrition. Available online: https://www.who.int/nutrition/double-burdenmalnutrition/en/\#: \{\}:text=Double\%20burden\%20of\%20malnutrition,populations $\% 2$ C $\% 20$ and $\% 20$ across $\%$ 20the\%20lifecourse (accessed on 1 June 2020).

8. Djordjic, V.; Jorga, J.; Radisavljevic, S.; Milanovic, I.; Bozic, P.; Ostojic, S.M. Thinness in young schoolchildren in Serbia: Another case of the double burden of malnutrition? Public Health Nutr. 2018, 21, 877-881. [CrossRef] [PubMed]

9. Global Burden of Disease Collaborators Health effects of overweight and obesity in 195 countries over 25 years. N. Engl. J. Med. 2017, 377, 13-27. [CrossRef]

10. WHO. World Health Organization Global Monitoring Framework for NCDs: Target 7: Halt the Rise in Obesity. Available online: https://www.who.int/nmh/ncd-tools/target7/en/ (accessed on 1 June 2020).

11. United Nations. Sustainable Development Goals. Available online: https://sustainabledevelopment.un.org/ ?menu=1300 (accessed on 28 June 2020).

12. Sachs, J.; Schmidt-Traub, G.; Kroll, C.; Lafortune, G.; Fuller, G. Sustainable Development Report 2019; Bertelsmann Stiftung and Sustainable Development Solutions Network (SDSN): New York, NY, USA, 2019; Volume 2.

13. Mikkilä, V.; Räsänen, L.; Raitakari, O.T.; Pietinen, P.; Viikari, J. Longitudinal changes in diet from childhood into adulthood with respect to risk of cardiovascular diseases: The Cardiovascular Risk in Young Finns Study. Eur. J. Clin. Nutr. 2004, 58, 1038-1045. [CrossRef]

14. WHO. Increasing Fruit and Vegetable Consumption to Reduce the Risk of Noncommunicable Diseases; World Health Organization: Geneva, Switzerland, 2014.

15. WHO. Diet, Nutrition and the Prevention of Chronic Diseases: Report of a Joint WHO/FAO Expert Consultation; WHO Technical Report Series, No. 916; World Health Organization: Geneva, Switzerland, 2003.

16. WHO. Guideline: Sugars Intake for Adults and Children; World Health Organization: Geneva, Switzerland, 2015.

17. Mozaffarian, D.; Fahimi, S.; Singh, G.M.; Micha, R.; Khatibzadeh, S.; Engell, R.E.; Lim, S.; Danaei, G.; Ezzati, M.; Powles, J.; et al. Global sodium consumption and death from cardiovascular causes. N. Engl. J. Med. 2014, 371, 624-634. [CrossRef]

18. Malik, V.S.; Pan, A.; Willett, W.C.; Hu, F.B. Sugar-sweetened beverages and weight gain in children and adults: A systematic review and meta-analysis. Am. J. Clin. Nutr. 2013, 98, 1084-1102. [CrossRef]

19. Moynihan, P.J.; Kelly, S.A.M. Effect on caries of restricting sugars intake: Systematic review to inform WHO guidelines. J. Dent. Res. 2014, 93, 8-18. [CrossRef] 
20. Wijnhoven, T.M.; van Raaij, J.; Breda, J. WHO European Childhood Obesity Surveillance Initiative. Implementation of Round 1 (2007/2008) and Round 2 (2009/2010); WHO Regional Office for Europe: Copenhagen, Denmark, 2014.

21. Council for International Organizations of Medical Sciences, Council for International Organizations of Medical Sciences, World Health Organization. International Ethical Guidelines for Biomedical Research Involving Human Subjects; World Health Organization: Geneva, Switzerland, 2002.

22. Wijnhoven, T.M.; van Raaij, J.M.; Spinelli, A.; Rito, A.I.; Hovengen, R.; Kunesova, M.; Starc, G.; Rutter, H.; Sjoberg, A.; Petrauskiene, A.; et al. WHO European Childhood Obesity Surveillance Initiative 2008: Weight, height and body mass index in 6-9-year-old children. Pediatr. Obes. 2013, 8, 79-97. [CrossRef] [PubMed]

23. WHO. European Childhood Obesity Surveillance Initiative: Overweight and Obesity among 6-9-year-old Children. Report of the Third Round of Data Collection 2012-2013; WHO: Geneva, Switzerland, 2018.

24. WHO. Healthy Diet: Key Facts. Available online: https://www.who.int/news-room/fact-sheets/detail/healthydiet (accessed on 29 June 2020).

25. United Nations. Statistical Division Standard Country or Area Codes for Statistical Use (M49). Available online: https://unstats.un.org/unsd/methodology/m49/ (accessed on 6 August 2020).

26. Monzani, A.; Ricotti, R.; Caputo, M.; Solito, A.; Archero, F.; Bellone, S.; Prodam, F. A systematic review of the association of skipping breakfast with weight and cardiometabolic risk factors in children and adolescents. What should we better investigate in the future? Nutrients 2019, 11, 387. [CrossRef] [PubMed]

27. Inchley, J.; Currie, D.B.; Budisavljevic, S.; Torsheim, T.; Jåstad, A.; Cosma, A.; Kelly, C.; Arnarsson, Á. Spotlight on Adolescent Health and Well-Being: Findings from the 2017/2018 Health Behaviour in School-Aged Children (HBSC) Survey in Europe and Canada; WHO Regional Office for Europe: Copenhagen, Denmark, 2020.

28. Vereecken, C.; Pedersen, T.P.; Ojala, K.; Krølner, R.; Dzielska, A.; Ahluwalia, N.; Giacchi, M.; Kelly, C. Fruit and vegetable consumption trends among adolescents from 2002 to 2010 in 33 countries. Eur. J. Public Health 2015, 25, 16-19. [CrossRef]

29. Rosi, A.; Paolella, G.; Biasini, B.; Scazzina, F.; Alicante, P.; De Blasio, F.; dello Russo, M.; Paolella, G.; Rendina, D.; Rosi, A. Dietary habits of adolescents living in North America, Europe or Oceania: A review on fruit, vegetable and legume consumption, sodium intake, and adherence to the Mediterranean Diet. Nutr. Metab. Cardiovasc. Dis. 2019, 29, 554-560. [CrossRef] [PubMed]

30. Scaglioni, S.; De Cosmi, V.; Ciappolino, V.; Parazzini, F.; Brambilla, P.; Agostoni, C. Factors Influencing Children's Eating Behaviours. Nutrients 2018, 10, 706. [CrossRef] [PubMed]

31. Smith, R.; Kelly, B.; Yeatman, H.; Boyland, E. Food marketing influences children's attitudes, preferences and consumption: A systematic critical review. Nutrients 2019, 11, 875. [CrossRef] [PubMed]

32. Micha, R.; Karageorgou, D.; Bakogianni, I.; Trichia, E.; Whitsel, L.P.; Story, M.; Penalvo, J.L.; Mozaffarian, D. Effectiveness of school food environment policies on children's dietary behaviors: A systematic review and meta-analysis. PLoS ONE 2018, 13, e0194555. [CrossRef]

33. European Commission. School Fruit, Vegetables and Milk Scheme. Available online: https://ec.europa.eu/info/food-farming-fisheries/key-policies/common-agricultural-policy/marketmeasures/school-fruit-vegetables-and-milk-scheme (accessed on 25 May 2020).

34. WHO. Nutrition-Friendly Schools Initiative (NFSI). Available online: https://www.who.int/nutrition/topics/ nutrition_friendly_schools_initiative/en/ (accessed on 25 May 2020).

35. U.S. Department of Agriculture. School Breakfast Program. Available online: https://www.fns.usda.gov/sbp/ school-breakfast-program (accessed on 26 May 2020).

36. WHO. Taxes on Sugary Drinks: Why Do It? World Health Organization: Geneva, Switzerland, 2017.

37. Colchero, M.A.; Rivera-Dommarco, J.; Popkin, B.M.; Ng, S.W. In Mexico, Evidence of Sustained Consumer Response two Years after Implementing a Sugar-Sweetened Beverage Tax. Health Aff. (Millwood) 2017, 36, 564-571. [CrossRef]

38. van Raaij, J.; Hendriksen, M.; Verhagen, H. Potential for improvement of population diet through reformulation of commonly eaten foods. Public Health Nutr. 2009, 12, 325-330. [CrossRef]

39. Goiana-da-Silva, F.; Cruz, E.S.D.; Gregorio, M.J.; Miraldo, M.; Darzi, A.; Araujo, F. The future of the sweetened beverages tax in Portugal. Lancet Public Health 2018, 3, e562. [CrossRef]

40. Griffith, R.; O'Connell, M.; Smith, K. The Importance of Product Reformulation Versus Consumer Choice in Improving Diet Quality. Economica 2017, 84, 34-53. [CrossRef]

41. Macgregor, G.A.; Hashem, K.M. Action on sugar-lessons from UK salt reduction programme. Lancet 2014, 383, 929-931. [CrossRef] 
42. Cairns, G.; Angus, K.; Hastings, G.; Caraher, M. Systematic reviews of the evidence on the nature, extent and effects of food marketing to children. A retrospective summary. Appetite 2013, 62, 209-215. [CrossRef] [PubMed]

43. WHO. Monitoring and Restricting Digital Marketing of Unhealthy Products to Children and Adolescents; World Health Organization Regional Office for Europe: Copenhagen, Denmark, 2019.

44. WHO. Noncommunicable Diseases Progress Monitor; World Health Organization: Geneva, Switzerland, 2017.

45. Hodder, R.K.; O’Brien, K.M.; Tzelepis, F.; Wyse, R.J.; Wolfenden, L. Interventions for increasing fruit and vegetable consumption in children aged five years and under. Cochrane Database Syst. Rev. 2018, 2018, CD008552. [CrossRef]

46. Mazarello Paes, V.; Hesketh, K.; O’Malley, C.; Moore, H.; Summerbell, C.; Griffin, S.; Van Sluijs, E.M.F.; Ong, K.K.; Lakshman, R. Determinants of sugar-sweetened beverage consumption in young children: A systematic review. Obes. Rev. 2015, 16, 903-913. [CrossRef]

47. Kairey, L.; Matvienko-Sikar, K.; Kelly, C.; McKinley, M.C.; O'Connor, E.M.; Kearney, P.M.; Woodside, J.V.; Harrington, J.M. Plating up appropriate portion sizes for children: A systematic review of parental food and beverage portioning practices. Obes. Rev. 2018, 19, 1667-1678. [CrossRef]

48. WHO. Report of the Commission on Ending Childhood Obesity; World Health Organization: Geneva, Switzerland, 2016.

49. Crockett, R.A.; King, S.E.; Marteau, T.M.; Prevost, A.T.; Bignardi, G.; Roberts, N.W.; Stubbs, B.; Hollands, G.J.; Jebb, S.A. Nutritional labelling for healthier food or non-alcoholic drink purchasing and consumption. Cochrane Database Syst. Rev. 2018, 2, CD009315. [CrossRef]

50. Monsivais, P.; Aggarwal, A.; Drewnowski, A. Are socio-economic disparities in diet quality explained by diet cost? J. Epidemiol. Community Health 2012, 66, 530-535. [CrossRef]

51. Spinelli, A.; Buoncristiano, M.; Kovacs, V.A.; Yngve, A.; Spiroski, I.; Obreja, G.; Starc, G.; Pérez, N.; Rito, A.I.; Kunešová, M. Prevalence of severe obesity among primary school children in 21 European countries. Obes. Facts 2019, 12, 244-258. [CrossRef]

52. Pérez-Rodrigo, C.; Artiach Escauriaza, B.; Artiach Escauriaza, J.; Polanco Allúe, I. Dietary assessment in children and adolescents: Issues and recommendations. Nutr. Hosp. 2015, 31 (Suppl. 3), 76-83. [CrossRef]

53. Medin, A.C.; Hansen, B.H.; Astrup, H.; Ekelund, U.; Frost Andersen, L. Validation of energy intake from a web-based food recall for children and adolescents. PLoS ONE 2017, 12, e0178921. [CrossRef] [PubMed]

54. Cheung, K.L.; Peter, M.; Smit, C.; de Vries, H.; Pieterse, M.E. The impact of non-response bias due to sampling in public health studies: A comparison of voluntary versus mandatory recruitment in a Dutch national survey on adolescent health. BMC Public Health 2017, 17, 276. [CrossRef] [PubMed]

55. Berg, C.; Jonsson, I.; Conner, M.T.; Lissner, L. Sources of bias in a dietary survey of children. Eur. J. Clin. Nutr. 1998, 52, 663-667. [CrossRef] [PubMed]

(C) 2020 by the World Health Organization. Licensee MDPI, Basel, Switzerland. This is an open access article distributed under the terms of the Creative Commons Attribution IGO License ( http://creativecommons.org/licenses/by/3.0/igo/legalcode), which permits unrestricted use, distribution, and reproduction in any medium, provided the original work is properly cited. In any reproduction of this article there should not be any suggestion that WHO or this article endorse any specific organisation or products. The use of the WHO logo is not permitted. This notice should be preserved along with the article's original URL. 